HEAD AND NECK

\title{
Surgical site infections after parotidectomy: management and benefits of an antibiotic prophylaxis protocol
}

\author{
Infezioni del sito chirurgico dopo parotidectomia: \\ la gestione e i vantaggi dell'antibioticoprofilassi \\ G. MECCARIELLO, F. MONTEVECCHI, G. D’AGOSTINO, E. ZECCARDO, M.F.H. AL-RASWASHDEH, \\ A. DE VITO, C. VICINI \\ Department of Head-Neck Surgery, Otolaryngology, Head-Neck and Oral Surgery Unit, Morgagni Pierantoni \\ Hospital, Forlì and degli Infermi Hospital, Faenza, Azienda USL della Romagna, Italy
}

\section{SUMMARY}

The use of perioperative prophylactic antibiotics in uncontaminated head and neck surgery is still controversial. The aim of this study was to assess the efficacy of an institutional antibiotic prophylactic protocol in preventing surgical site infection after parotidectomy. The medical charts of 448 patients who underwent parotidectomy were reviewed. Patients were divided in two groups according the use of perioperative administration of intravenous cefazolin or post-operative week course of antibiotics. Surgical site infection was registered in 29 (6.5\%) cases, $16(5.7 \%)$ within the group before the application of the perioperative protocol and $13(7.9 \%)$ within the antibiotic prophylaxis protocol group. The univariate and multivariate logistic regression analyses showed that predictors for surgical site infection were the amount of drain output $\geq 50 \mathrm{ml}$ in the first post-operative 24 hours (OR: 4.86; 1.59-14.82 95\% CI; $\mathrm{p}<0.01$ ) and history of a previous parotid acute infection (OR: 13.83; 5.31-36 95\% CI; $\mathrm{p}<0.01)$. The majority of post-surgical infections $(82 \%)$ were treated with intravenous antibiotic therapy. The remnants were treated surgically. Perioperative antibiotic treatment is recommended for patients undergoing parotid gland surgery and intravenous antibiotics during the postoperative course are highly suggested in case of history of previous acute parotid infection and drain output $\geq 50 \mathrm{ml}$ in first 24 hours.

KEY WORDS: Surgical site infection $\bullet$ Parotidectomy $\bullet$ Surgery $\bullet$ Prophylaxis $\bullet$ Antibiotic

\section{RIASSUNTO}

L'uso dell'antibioticoprofilassi perioperatoria nella chirurgia della testa e del collo non contaminati è ancora oggetto di dibattito. La valutazione dell'efficacia del protocollo istituzionale di antibioticoprofilassi per la prevenzione dell'infezione del sito chirurgico dopo parotidectomia è l'obiettivo del nostro studio. Per tale scopo sono state rivalutate le cartelle cliniche di 448 pazienti sottoposti a parotidectomia. I pazienti sono stati divisi in due gruppi in base all'uso della somministrazione endovenosa perioperatoria di cefazolina oppure di ciclo settimanale di antibioticoterapia post-operatoria. L'infezione del sito chirurgico è stata registrata in 29 casi (6,5\%) di cui 16 (5,7\%) all'interno del gruppo prima dell'applicazione del protocollo perioperatorio e 13 (7,9\%) all'interno del gruppo dell'antibioticoprofilassi. Le analisi di regressione logistica univariata e multivariata hanno mostrato che i fattori predittivi per l'infezione del sito chirurgico erano la quantità di raccolta nel drenaggio $\geq 50 \mathrm{ml}$ nelle prime 24 ore postoperatorie (OR: 4,86; 1,59-14,82 95\% CI; $p<0,01)$ e l'anamnesi positiva per una precedente infezione acuta parotidea (OR: 13,83; 5,31-36 95\% CI; $p$ <0,01). La maggior parte delle infezioni post-chirurgiche (82\%) sono state trattate con terapia antibiotica endovenosa. Le restanti hanno richiesto un intervento chirurgico. L'antibioticoprofilassi è raccomandata per i pazienti sottoposti a chirurgia parotidea mentre la terapia antibiotica nel decorso post-operatorio è fortemente consigliata in caso di storia di precedenti infezioni acute parotidee e di quantità di materiale raccolto nel drenaggio $\geq 50 \mathrm{ml}$ nelle prime 24 ore.

PAROLE CHIAVE: Infezione del sito chirurgico $\bullet$ Parotidectomia $\bullet$ Chirurgia $\bullet$ Profilassi $\bullet$ Antibiotico

\section{Introduction}

Antibiotic stewardship is critical, but there is limited evidence to guide surgeons on the most appropriate regimen for antibiotic prophylaxis during head and neck surgery. Antibiotic prophylaxis in clean-contaminated head and neck surgery is mandatory. The efficacy of perioperative antibiotic administration during major head and neck surgery in which the wound is contaminated by saliva has been clearly established. Some head and neck surgeons believe that during parotidectomy a direct connection between the oral cavity and the surgical field is formed with possible retrograde flow of saliva from the contaminated oral cavity 
into the clean wound. Hence, they advocate the use of prophylactic perioperative antibiotic treatment in parotid gland surgery. Slattery et al. ${ }^{1}$ found that perioperative antibiotic prophylaxis for 24 hours is sufficient to prevent wound infections in clean, uncontaminated neck dissections. However, the use of perioperative prophylactic antibiotics in uncontaminated head and neck surgery remains controversial ${ }^{2}$. Furthermore, the choice of specific antimicrobial agents and duration of treatment are controversial, and incidence of the reported wound infections in head-neck surgery is still high ${ }^{34}$. Cephalosporins have emerged as the drug of choice for perioperative prophylaxis because of their wide antibacterial spectrum and low incidence of side effects ${ }^{5}$.

The purpose of this study is to compare the efficacy of our institutional antibiotic prophylaxis protocol with a cefazolin regimen given as a single dose rather than as a one week course of antibiotic in preventing surgical site infection (SSI) after parotidectomy.

\section{Materials and methods}

This study was approved by the Institutional Review Board. The medical charts of consecutive patients who underwent parotidectomy at our department between November 2004 and March 2016 were evaluated retrospectively. Data collected for the analysis were: age, sex, comorbidities, pathology, postoperative complications and follow-up data, including postoperative wound infection, drainage amount, type and route of antibiotics administration and type of surgery. Patients were excluded if they had undergone previously parotid surgery, if there was missing information about wound infection, or missing information about the receipt of antibiotics. All patients were prepared and draped for surgery in the same fashion using povidone-iodine, $10 \%$, topical solution. At our institution before 2013, surgeons administered oral amoxicillin/clavulanic acid $1 \mathrm{gm}$ every 8 hours for one week in the post-operative course. If penicillin allergy was noted, ciprofloxacin $500 \mathrm{mg}$ each 12 hours for a week or clarithromycin $500 \mathrm{mg}$ each 12 hours for a week. After 2013, a perioperative antibiotic prophylaxis institutional protocol was introduced. Immediately before the skin incision, intravenous cefazolin $2 \mathrm{gm}$ is currently administered. If penicillin allergy was registered, intravenous clarithromycin $500 \mathrm{mg}$ or, as second choice, ciprofloxacin $500 \mathrm{mg}$ is given in a single shot.

The SSI was defined as local oedema, erythema and tenderness, starting no less than 48 hours postoperatively.

Statistical analysis

To test the differences among groups Fisher's exact test was used for categorical data, while the Student's t-test was used for continuous data. The role of each possible prognostic factor (univariate analysis) and their independent effect (multivariate analysis) was explored using logistic regression model or Cox-proportional hazard model as appropriate. Probability values lower than 0.05 were considered statistically significant. All analyses were performed with STATA 12.1 software (Stata Corp, College Station, TX, USA).

\section{Results}

A total of 448 patients met inclusion criteria. The patients were divided in two groups according the perioperative antibiotic prophylactic protocol. The cohort's characteristics are shown in Table I. Perioperative antibiotic treatment was given to 165 patients $(36.8 \%)$. No significant differences were found between groups, except for the extent of parotidectomy $(\mathrm{p}<0.01)$. More radical parotidectomies within the group before the application of perioperative antibiotic prophylaxis protocol were recorded. However, the groups can be considered homogenous. SSI was registered in $29(6.5 \%)$ of 448 cases, 16 (5.7\%) within the group before the application of antibiotic prophylaxis protocol and $13(7.9 \%)$ within the antibiotic prophylaxis protocol group $(p=0.43)$. The majority of SSIs $(82 \%)$ were treated with intravenous antibiotic therapy. Four patients needed a surgical drainage of the pus collection, while only one patient needed complete surgical revision for extension of the neck abscess in the deep fascial plane surrounding the main neurovascular bundle.

Of note, 132 Warthin's tumours were found and at least one previous infection's episode was noted in $10.6 \%$ of cases. Moreover, previous parotid infections were registered in $81 \%$ of chronic sialoadenitis with calculi. Univariate and multivariate logistic regression analyses (Table II) showed that predictors for SSI were the amount of drain output $\geq 50 \mathrm{ml}$ in the first post-operative 24 hours (OR: 4.86; 1.59-14.82 95\% CI; p < 0.01) and history of previous acute parotid infection (OR: 13.83; 5.31-36 95\% CI; $\mathrm{p}<0.01)$.

\section{Discussion}

Despite remarkable advances in the use of surgical techniques and prophylactic antibiotics and environmental/ergonomic improvements in the operating room, SSIs remain a significant cause of patient morbidity and mortality, and are the third-most common source of hospital-acquired infection ${ }^{6}$. Of concern is that SSIs occur in up to $30 \%$ of all surgical procedures, and yet most are preventable ${ }^{67}$. 
Table I. Clinical characteristics of 448 patients undergoing parotidectomy.

\begin{tabular}{|c|c|c|c|}
\hline & No perioperative prophylaxis (\%) & Perioperative prophylaxis protocol (\%) & $p$ \\
\hline \multicolumn{4}{|l|}{ Sex } \\
\hline Males & $162(57.2)$ & $87(52.7)$ & \multirow{2}{*}{0.38} \\
\hline Females & $121(42.8)$ & $78(47.3)$ & \\
\hline Age (mean \pm SD) & $57.8 \pm 16.4$ & $59 \pm 16$ & 0.46 \\
\hline \multicolumn{4}{|l|}{ Diabetes } \\
\hline Yes & $24(8.5)$ & $7(4.2)$ & \multirow{2}{*}{0.12} \\
\hline No & $259(91.5)$ & $158(95.8)$ & \\
\hline \multicolumn{4}{|l|}{ Histology } \\
\hline Benign & $250(88.3)$ & $147(89.1)$ & \multirow{2}{*}{0.88} \\
\hline Malignant & $33(11.7)$ & $18(10.9)$ & \\
\hline \multicolumn{4}{|c|}{ Type of parotidectomy } \\
\hline Superficial/partial & $250(88.3)$ & $156(94.6)$ & \multirow{3}{*}{$p<0.01$} \\
\hline Total & $16(5.7)$ & $8(4.9)$ & \\
\hline Radical & $17(6)$ & $1(0.6)$ & \\
\hline \multicolumn{4}{|l|}{ Neck dissection } \\
\hline Yes & $30(10.4)$ & $9(5.4)$ & \multirow{2}{*}{0.08} \\
\hline No & $253(89.4)$ & $156(94.6)$ & \\
\hline \multicolumn{4}{|c|}{ Drain output first 24 hours } \\
\hline$<50 \mathrm{ml}$ & $136(48.1)$ & $67(40.6)$ & \multirow{2}{*}{0.14} \\
\hline$\geq 50 \mathrm{ml}$ & $147(51.9)$ & $98(59.4)$ & \\
\hline \multicolumn{4}{|l|}{ Previous infection } \\
\hline Yes & 21 (7.42) & $18(10.9)$ & \multirow{2}{*}{0.23} \\
\hline No & 262 (92.58) & $147(89.1)$ & \\
\hline \multicolumn{4}{|c|}{ Surgical site infection } \\
\hline Yes & $16(5.7)$ & $13(7.9)$ & \multirow{2}{*}{0.43} \\
\hline No & 267 (94.3) & $152(92.1)$ & \\
\hline
\end{tabular}

SD = standard deviation

The economic impacts on the health care system are substantial, including increased hospital length of stay and escalating hospital costs, rising from twofold to fivefold ${ }^{8}$. These human and economic effects are compounded by overstretched health care systems, suboptimal integration in clinical processes and fragmented approaches used by health professionals in wound-care management. Necessarily, there is a growing emphasis on the prevention of SSI. Unfortunately, no randomised controlled studies hitherto are present in literature analysing the best care in preventing SSI after parotidectomy. Recently, Shkedy et al. ${ }^{9}$ demonstrated that female sex, neck dissection and drain output $>50 \mathrm{ml}$ within 24 hours were predictive of postoperative wound infection after parotidectomy and found no benefit for routine prophylactic perioperative antibiotic treatment in patients undergoing parotid gland surgery. On the other hand, our results confirm, at univariate and multivariate logistic regression analysis, that drain output $>50 \mathrm{ml}$ within 24 hours $(\mathrm{p}<0.01)$ and, further, a history of previous parotid infections $(\mathrm{p}<0.01)$ were predictive of SSIs. Interestingly, the slightly high prevalence but not statistically significant of SSIs in the antibiotic prophylaxis group (7.9\% vs $5.7 \%$ ) might be explained by the fact that cases with a history of previous infections require antibiotics postoperatively and the prophylaxis is not adequately sufficient.

In the literature, few studies have evaluated the efficacy of antibiotic prophylaxis in prevention of SSIs in head and neck surgery, and most of them addressed purely major oncological surgery not discussing parotid gland surgery as a separate entity. Simo and French ${ }^{10}$ found that prophylactic antibiotic use in clean-contaminated major oncological head and neck surgery is mandatory to reduce the risk of infection. Ogihara et al. ${ }^{11}$ concluded that in order to minimise SSI, patients with head and neck tumours should have a thorough understanding of the risk factors leading to postoperative infections, such as blood loss, previous chemotherapy and clean-contaminated sur- 
Table II. Univariate and logistic multivariate regression analysis of predicting factors for surgical site infection.

\begin{tabular}{|c|c|c|c|c|c|c|c|c|}
\hline & \multicolumn{3}{|c|}{ Univariate } & \multicolumn{5}{|c|}{ Multivariate } \\
\hline & $\begin{array}{l}\text { Number of surgical } \\
\text { site infections (\%) }\end{array}$ & Odds ratio & $p$ & Odds ratio & Std. Err. & $z$ & $p$ & $\begin{array}{l}95 \% \text { Confidence } \\
\text { interval }\end{array}$ \\
\hline \multicolumn{9}{|l|}{ Sex } \\
\hline Males & $21(8.5)$ & 2.2 & 0.65 & 1.89 & 0.89 & 1.36 & 0.17 & $0.76,4.75$ \\
\hline Females & $8(4)$ & \multicolumn{2}{|c|}{1 (Reference) } & \multicolumn{5}{|c|}{1 (Reference) } \\
\hline \multicolumn{9}{|l|}{ Age at diagnosis } \\
\hline$<60$ years & $13(5.8)$ & \multicolumn{2}{|c|}{1 (Reference) } & \multicolumn{5}{|c|}{1 (Reference) } \\
\hline$\geq 60$ years & $16(7.14)$ & 1.25 & 0.57 & 1.05 & 0.46 & 0.10 & 0.92 & $0.44,2.46$ \\
\hline \multicolumn{9}{|l|}{ Diabetes } \\
\hline Yes & $2(6.5)$ & \multicolumn{2}{|c|}{1 (Reference) } & \multicolumn{5}{|c|}{1 (Reference) } \\
\hline No & $27(6.5)$ & 1 & 1 & 1.18 & 0.99 & 0.19 & 0.85 & $0.22,6.2$ \\
\hline \multicolumn{9}{|l|}{ Histology } \\
\hline Benign & $24(6.1)$ & 1.69 & 0.31 & 3.46 & 2.28 & 1.89 & 0.06 & $0.95,12.6$ \\
\hline Malignant & $5(9.8)$ & \multicolumn{2}{|c|}{1 (Reference) } & \multicolumn{5}{|c|}{1 (Reference) } \\
\hline \multicolumn{9}{|c|}{ Type of parotidectomy } \\
\hline Superficial/partial & $25(6.2)$ & 1.56 & 0.19 & 1.23 & 0.68 & 0.38 & 0.71 & $0.42,3.65$ \\
\hline Total & $1(4.2)$ & \multicolumn{2}{|c|}{1 (Reference) } & \multicolumn{5}{|c|}{1 (Reference) } \\
\hline Radical & $3(16.7)$ & \multicolumn{2}{|c|}{1 (Reference) } & \multicolumn{5}{|c|}{1 (Reference) } \\
\hline \multicolumn{9}{|l|}{ Neck dissection } \\
\hline Yes & 4 (10.3) & 1.76 & 0.32 & 0.52 & 0.46 & -0.75 & 0.45 & $0.09,2.91$ \\
\hline No & $25(6.1)$ & \multicolumn{2}{|c|}{1 (Reference) } & \multicolumn{5}{|c|}{11 (Reference) } \\
\hline \multicolumn{9}{|c|}{ Drain output first 24 hours } \\
\hline$<50 \mathrm{ml}$ & $4(2)$ & \multicolumn{2}{|c|}{1 (Reference) } & \multicolumn{5}{|c|}{1 (Reference) } \\
\hline$\geq 50 \mathrm{ml}$ & 25 (10.2) & 5.65 & $<0.01$ & 4.86 & 2.76 & 2.78 & $<0.01$ & $1.59,14.82$ \\
\hline \multicolumn{9}{|l|}{ Previous infection } \\
\hline Yes & $13(33.3)$ & 12.28 & $<0.01$ & 13.83 & 6.75 & 5.38 & $<0.01$ & $5.31,36$ \\
\hline No & $16(3.91)$ & \multicolumn{2}{|c|}{1 (Reference) } & \multicolumn{5}{|c|}{1 (Reference) } \\
\hline \multicolumn{9}{|c|}{ Perioperative antibiotics } \\
\hline Yes & $13(7.9)$ & $1(\mathrm{R}$ & ence) & & & 1 (Refere & & \\
\hline No & $16(5.7)$ & 0.7 & 0.36 & 1.19 & 0.53 & 0.39 & 0.69 & $0.5,2.8$ \\
\hline
\end{tabular}

Std. Err. = standard error.

gery. Lee et al. ${ }^{12}$ recommended preventive measures or close monitoring in these patients to reduce the likelihood of postoperative SSIs. Busch et al. ${ }^{13}$, in a retrospective study, demonstrated that long-term (more than 7 days) antibiotic prophylaxis is not associated with a further decrease in SSI rates in head neck oncologic surgery. Conversely, Carrau et al. ${ }^{2}$ did not demonstrate the efficacy of prophylactic antibiotics in uncontaminated neck dissections.

Selection of the appropriate antimicrobial agent for a specific surgery should take into account characteristics of the ideal agent, comparative efficacy of the antimicrobial agent for the procedure, safety profile and the patient's medication allergies. To achieve these goals, an antimicrobial agent should be active against the pathogens most likely to contaminate the surgical site; given in an appropriate dosage and at a time that ensures adequate serum and tissue concentrations during the period of potential contamination, and administered for the shortest effective period to minimise adverse effects, development of resistance and costs. Generally, for most surgical procedures, cefazolin is the drug of choice for prophylaxis because it is the most widely studied antimicrobial agent, with proven efficacy. It has a desirable duration of action, spectrum of activity against organisms commonly encountered in surgery, reasonable safety and low cost ${ }^{14}$. In case of unresponsive SSIs to antibiotics, surgical intervention remains the mainstay of treatment, especially in severe cases of deep neck infections. Indications for surgery include airway impairment, septicaemia, de- 


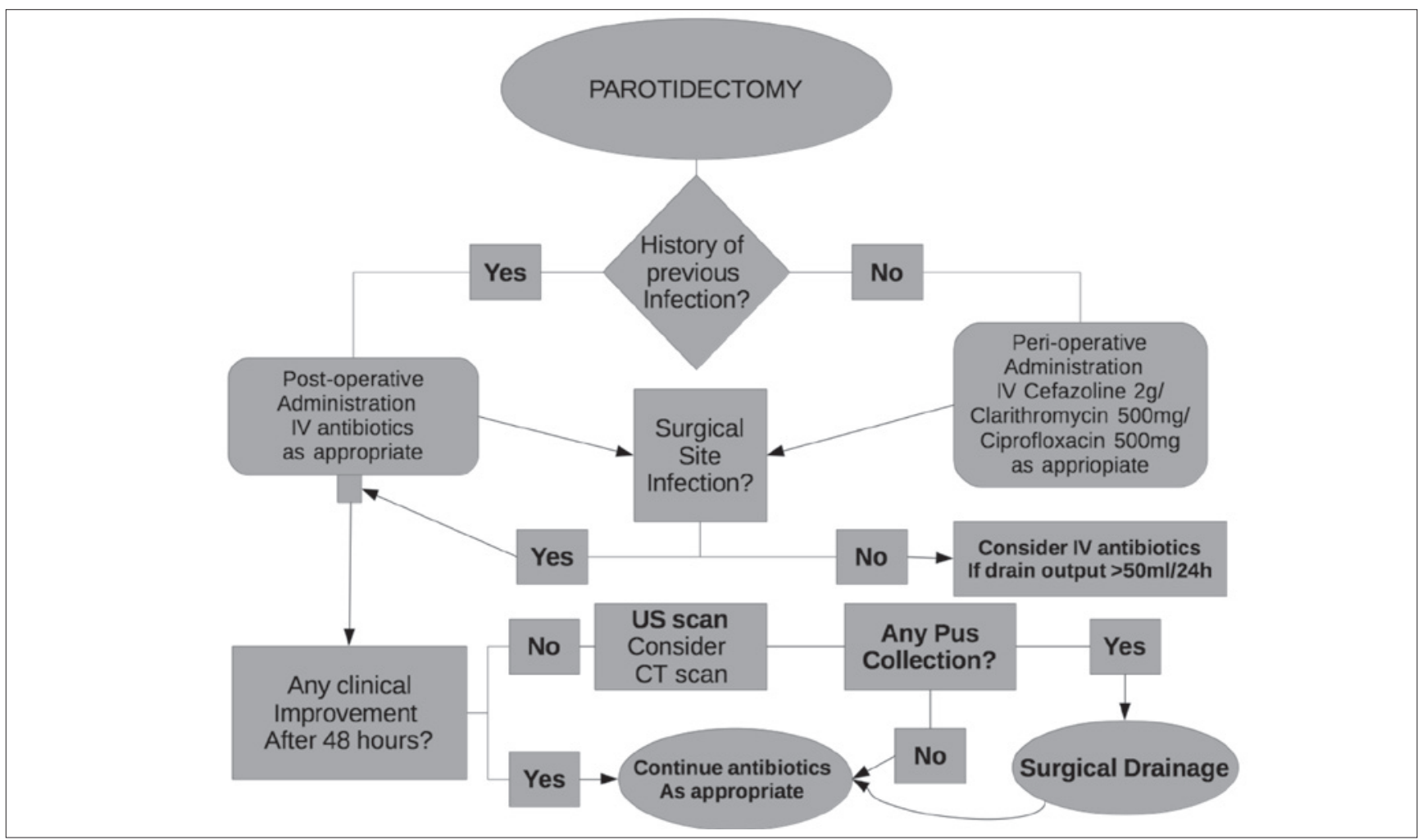

Fig. 1. Institutional algorithm of decision-making and management of post-operative course after parotidectomy.

scending infection, diabetes mellitus, or no clinical improvement within 48 hours from intravenous antibiotic administration ${ }^{15}$. In addition, abscesses $>3 \mathrm{~cm}$ in diameter that involve the prevertebral, anterior visceral, or carotid spaces, or that involve more than two spaces, should be surgically drained ${ }^{16}$. Conventionally, once surgical drainage has been completed, drainage tubes, usually in continuous aspiration, are placed in the surgical field to remove all secretions and prevent new pus collection from forming in the postoperative course. Recently, the VAC therapy has gained wide acceptance for the management of complex wound infections ${ }^{17}$. Gallo et al. ${ }^{18}$ used this device in deep neck abscess with promising results.

In our point of view, we strongly support the use of VAC in case of extended and/or severe cases of SSIs needing surgical drainage, although attention should be given avoiding the direct application on the facial nerve. Nevertheless, this device permits to obtain a larger surface area under negative pressure. This characteristic makes VAC more effective in eliminating the biofilm that protects bacteria from antibiotics and in promoting healing through the enhancement of granulation tissue formation ${ }^{19}$.

Furthermore, as SSIs are a key indicator of quality care, it is important to implement strategies that promote team- based approaches in their prevention. For these reasons, we developed an algorithm for prophylactic antibiotic and relative SSI treatment in parotid gland surgery to help clinicians in decision-making and patient management (Fig. 1).

\section{Conclusions}

Perioperative antibiotic treatment is recommended for patients undergoing parotid gland surgery and intravenous antibiotics during the post-operative course are highly suggested in case of history of previous acute parotid infection and of drain output $\geq 50 \mathrm{ml}$ in first 24 hours.

\section{Conflict of interest statement}

None declared.

\section{References}

1 Slattery WH III, Stringer SP, Cassisi NJ. Prophylactic antibiotic use in clean, uncontaminated neck dissection. Laryngoscope 1995;105:244-6.

2 Carrau RL, Byzakis J, Wagner RL, et al. Role of prophylactic antibiotics in uncontaminated neck dissections. Arch Otolaryngol Head Neck Surg 1991;117:194-5. 
3 Agra IM, Carvalho AL, Pontes E, et al. Postoperative complications after en bloc salvage surgery for head and neck cancer. Arch Otolaryngol Head Neck Surg 2003;129:1317-21.

4 Penel N, Fournier C, Lefebvre D, et al. Multivariate analysis of risk factors for wound infection in head and neck squamous cell carcinoma surgery with opening of mucosa. Study of 260 surgical procedures. Oral Oncol 2005;41:294-303.

5 Kaiser AB. Postoperative infections and antimicrobial prophylaxis. In: Mandell GL, Douglas RG, Bennett JE, editors. Principles and practice of infectious diseases. New York: Churchill Livingstone; 1990. pp. 2245-57.

6 Leaper DJ, Van Goor H, Reilly J, et al. Surgical site infection - a European perspective of incidence and economic burden. Int Wound J 1994;1:247-73.

7 Smyth ET, McIlvenny G, Enstone JE, et al. Four country healthcare associated infection prevalence survey 2006: overview of the results. J Hosp Infect 2008;69:230-48.

8 National Institute for Health and Care Excellence. Surgical site infection: prevention and treatment of surgical site infection. London: RCOG Press at the Royal College of Obstetricians and Gynaecologists; 2008.

9 Shkedy Y, Alkan U, Roman BR, et al. Role of perioperative antibiotic treatment in parotid gland surgery. Head Neck 2016;38:E1876-80.

10 Simo R, French G. The use of prophylactic antibiotics in head and neck oncological surgery. Curr Opin Otolaryngol Head Neck Surg 2006;14:55-61.

11 Ogihara H, Takeuchi K, Majima Y. Risk factors of postopera- tive infection in head and neck surgery. Auris Nasus Larynx 2009;36:457-60.

12 Lee DH, Kim SY, Nam SY, et al. Risk factors of surgical site infection in patients undergoing major oncological surgery for head and neck cancer. Oral Oncol 2011;47:528-31.

13 Busch CJ, Knecht R, Muncher A, et al. Postoperative antibiotic prophylaxis in clean-contaminated head and neck oncologic surgery: a retrospective cohort study. Eur Arch Otorhinolaryngol 2016;273:2805-11.

14 Bratzler DW, Dellinger EP, Olsen KM, et al. Clinical practice guidelines for antimicrobial prophylaxis in surgery. Am J Health Syst Pharm 2013;70:195-283.

15 Dellinger RP, Levy MM, Carlet JM, et al. Surviving sepsis campaign: international guidelines for management of severe sepsis and septic shock: 2008. Crit Care Med 2008;36:296-327.

16 Huang TT, Liu TC, Chen PR, et al. Deep neck infection: analysis of 185 cases. Head Neck 2004;26:854-60.

17 Batacchi S, Matano S, Nella A, et al. Vacuum-assisted closure device enhances recovery of critically ill patients following emergency surgical procedures. Crit Care 2009;13:R194.

18 Gallo O, Deganello A, Meccariello G, et al. Vacuum-assisted closure for managing neck abscesses involving the mediastinum. Laryngoscope 2012;122:785-8.

19 Ferguson DA Jr, Veringa EM, Mayberry W, et al. Bacteroides and staphylococcus glycocalyx: chemical analysis, and the effects on chemiluminescence and chemotaxis of human polymorphonuclear leucocytes. Microbios 1992;69:53-65.

Received: May 26, 2017 - Accepted: November 3, 2017

How to cite this article: Meccariello G, Montevecchi F, D'Agostino G, et al. Surgical site infections after parotidectomy: management and benefits of an antibiotic prophylaxis protocol. Acta Otorhinolaryngol Ital 2019;39:139-144. https://doi.org/10.14639/0392-100X-1768

Address for correspondence: Filippo Montevecchi, Department of Head-Neck Surgery, Otolaryngology, Head-Neck and Oral Surgery Unit, Morgagni Pierantoni Hospital, Azienda USL della Romagna, viale Forlanini 34, 47100 Forlì, Italy. Tel. +39 0543 735651. Fax +39 0543 735660. E-mail: filippomontevecchi72@gmail.com 